Journal Archives of Environmental Contamination and Toxicology

Issue Volume 52, Number 3 / April, 2007 : 431-440

http://dx.doi.org/10.1007/s00244-005-8225-9

(C2007 Springer Science+Business Media
Archimer, archive institutionnelle de l'Ifremer http://www.ifremer.fr/docelec/

The original publication is available at http://www.springerlink.com

\title{
Trace Elements in Three Marine Birds Breeding on Reunion Island (Western Indian Ocean): Part 2 - Factors Influencing Their Detoxification
}

\author{
J. Kojadinovic ${ }^{1,2,3,{ }^{*}}$ P. Bustamante ${ }^{1}$, M. Le Corre $^{2}$ and R. P. Cosson ${ }^{3}$
}

(1) CRELA. UMR 6217, CNRS-IFREMER- Université de La Rochelle, 22 Avenue Michel Crépeau, La Rochelle, F-17042, France

(2) Université de La Réunion, ECOMAR, 15 Avenue René Cassin, Saint Denis de La Réunion, F97715, France

(3) Université de Nantes, EMI, EA 2663, BP 92208, Nantes Cedex 3, F-44322, France

*: Corresponding author : Jessica.Kojadinovic@univ-nantes.fr Tel : +(33)2 51125691.

Fax : +(33)2 51125658 .

\begin{abstract}
:
Seabird tissues collected between 2002 and 2004 from Barau's Petrel (Pterodroma baraui), Audubon's Shearwater (Puffinus Iherminieri bailloni), and White-Tailed Trop icbird (Phaethon lepturus) colonies on Reunion Island were analyzed for metallothioneins (MTs) and trace element content. The subcellular distribution between soluble and insoluble fractions of $\mathrm{Cd}, \mathrm{Cu}, \mathrm{Fe}, \mathrm{Mn}, \mathrm{Se}$, and $\mathrm{Zn}$ was determined in liver and kidney. In both, the soluble fraction of the cell concentrated most of the $\mathrm{Cd}$ and $\mathrm{Se}$, whereas $\mathrm{Fe}, \mathrm{Mn}$, and $\mathrm{Zn}$ were preferentially accumulated in the insoluble fraction. The distribution of these elements varied with the tissue, age of the bird, and species. Furthermore, the distributions of $\mathrm{Fe}$ and $\mathrm{Mn}$ were somewhat influenced by the bird's physical condition. MT levels were measured in the soluble fraction after heat denaturation. The levels of these proteins varied from $5.5 \pm 2.7 \mathrm{mg} . \mathrm{g}-1$ dry weight ( $\mathrm{dw}$ ) to $11.4 \pm 6.2 \mathrm{mg} . \mathrm{g}-1 \mathrm{dw}$ depending on the species and the tissue considered. MT levels were significantly different between liver and kidney only in the White-Tailed Tropicbird. In the three species, MT levels in kidney were significantly higher in adult than juvenile birds. The bird's weight also had an influence on hepatic and renal MT levels, but not the sex nor the reproductive status. The implication of MTs in $\mathrm{Cu}$ and $\mathrm{Zn}$ homeostasis and $\mathrm{Cd}$ and $\mathrm{Hg}$ detoxification are discussed. In addition, clues on $\mathrm{Hg}$ regulation by Se were found, especially in Barau's Petrel, where the levels of these two elements were significantly correlated.
\end{abstract}




\section{Introduction}

Marine birds accumulate high levels of trace elements due to their position in marine food webs and their long life span. Cadmium $(\mathrm{Cd})$ and mercury $(\mathrm{Hg})$, which are often naturally present in the environment, are toxic to marine biota. Essential elements, such as copper $(\mathrm{Cu})$, iron $(\mathrm{Fe})$, manganese $(\mathrm{Mn})$, selenium (Se) and zinc $(\mathrm{Zn})$, are necessary for the metabolism but can however cause adverse effects when their concentrations in the organism becomes excessive. Quantification of trace element levels in different tissues of the organism is an indicator of the bioavailable fraction of the element in the environment (Hogstrand and Haux 1990). Nevertheless, these measures do not indicate whether the organism is stressed or affected by the contaminant. The physico-chemical form of storage of the element may however inform on the tissue(s) where detoxification takes place.

In marine vertebrates, detoxification is the result of many processes. One of the most commonly studied is the binding of metals to metallothioneins (Mason and Jenkins 1995). Metallothioneins (MTs) constitute a class of soluble low molecular weight metallo-proteins characterized by their heat stability, their high cystein content and a lack of aromatic amino acid (Hamer 1986). These proteins play an important role in the transport and storage of trace elements. They also provide protection against the toxic effects of certain metals by sequestrating and reducing the amount of free metal ions and acting as a "rescue" function for structures impaired by inappropriate metal-binding (Hamilton and Mehrle 1986, Vallee 1995, Roesijadi 1996). Since their discovery, in 1957, the existence of MTs was firmly established in a large number of animals (Hamza-Chaffai et al. 1995). MTs have been shown to occur in liver and/or in kidneys of various species of seabirds, such as Leach's Storm Petrel (Oceanodroma leucorhoa), the Atlantic Puffin (Fratercula arctica), the Doublecrested Cormorant (Phalacrocorax auritus), the Herring Gull (Larus argentatus), the Blackheaded Gull (Larus ridibundus), the Northern Fulmar (Fulmarus glacialis), the Guillemot (Uria aalge), the Kittiwake (Rissa tridactyla) and the Common Scoter (Melanitta nigra) (Osborn 1978, Elliott et al. 1992, Wenzel and Adelung 1996). Measurements of MT levels and their relationships with element levels constitute an attractive insight to trace element behavior in the organism.

Another common detoxification process relies on the insolubilization of metals as mineral concretions. A typical example is the formation of insoluble tiemannite granules after the binding of $\mathrm{Hg}$ by $\mathrm{Se}$ in the liver of many marine mammals and certain birds (Koeman et al. 1973, Martoja and Berry 1980, Nigro et al. 2002, Decataldo et al. 2004, Ikemoto et al. 2004). Enriched Cd granules are also known to exist in the White-sided dolphin (Lagenorhyncus acutus) kidneys (Gallien et al. 2001).

The nature of the detoxification process adopted by an organism gives an insight on its degree of exposure to toxic elements. For example, MTs tend to take part in the detoxification of elements to which the exposure is low or sudden (Chan et al. 1993), whereas granules attest the exposure to higher levels over a longer period of time (Palmisano et al. 1995).

Our work focuses on three seabird species breeding on Reunion Island which differ in their dietary ecology and in their contamination by elements as discussed in the first part of this study (Kojadinovic et al., submitted for this volume). Barau's Petrel (Pterodroma baraui) is an oceanic bird which feeds almost exclusively on cephalopods. Juveniles accumulate particularly high levels of $\mathrm{Hg}$ and $\mathrm{Cd}$, and adults mainly have high $\mathrm{Hg}, \mathrm{Fe}$ and $\mathrm{Se}$ levels. The White-tailed Tropicbird (Phaethon lepturus) also forages over oceanic water 
but closer to Reunion Island, and is less specialized on squid. In comparison to the other two species, high levels of $\mathrm{Cu}, \mathrm{Fe}, \mathrm{Mn}$ and $\mathrm{Zn}$ were observed in juveniles and $\mathrm{Cu}$ and $\mathrm{Mn}$ in adults. Finally, Aububon's Shearwater (Puffinus lherminieri bailloni) forages closest to the island, feeds as much on cephalopods as it does on fish (Bailey 1967, Jaquemet et al. 2004) and shows the lowest $\mathrm{Hg}$ levels (Kojadinovic et al., submitted for this volume). Information on species-specific differences in the sensitivity to trace elements would be important in evaluating the adverse effects of elements on wild birds.

Thus, in this second part of our work, we examine trace element regulation in Reunion seabirds by studying the subcellular distribution of trace elements and MT levels in liver and kidney as well as factors influencing MT levels. The interaction between MTs and Cd, $\mathrm{Cu}, \mathrm{Hg}, \mathrm{Zn}$, and the relationships between elements will be discussed in order to understand the potential detoxification strategies used by these birds.

\section{Materials and methods}

\subsection{Study site and species}

Barau's Petrel, Aububon's Shearwater and the White-tailed Tropicbird used in this study originated from colonies established on Reunion Island $\left(21^{\circ} 7 ' S, 55^{\circ} 33^{\prime} E\right)$ in the Western Indian Ocean. As noted earlier, these seabird species have contrasting dietary ecologies during their breeding season (approximately 3 months) during which they feed more or less in proximity to the island. Outside their breeding period, individuals scatter in the waters of the Indian Ocean (Barré et al. 1996, Stahl and Bartle 1991). During that time, dietary habits of the three species remain unknown.

\subsection{Bird sampling}

Fifty two Barau's Petrels, 61 Audubon's Shearwaters and 49 White-tailed Tropicbirds were sampled (Kojadinovic et al., submitted for this volume). Since these birds were found before or shortly after their accidental death, we are confident that the conditions in which the birds died had no effect on their elemental and MT levels. Each bird was measured, weighed and aged. Adults were sexed and their reproductive status noted. The liver, kidneys and pectoral muscles were removed during the dissection, weighed and refrozen prior to analysis. At this stage, the muscular and body conditions were evaluated by $\mathrm{MC}$ and $\mathrm{BC}$ indices respectively (Kojadinovic et al., submitted for this volume).

\subsection{Sample preparation}

To prepare for elemental and MT determination, livers and kidneys were blended, lyophilized and ground to a fine powder. One hundred $m g$ aliquots of tissue were homogenized on ice in $6 \mathrm{ml}$ of $100 \mathrm{mM}$ Tris buffer with $\beta$-mercaptoethanol at $p H=8.1$, then centrifuged. Metal content was determined in the pellet (C1). The obtained supernatant (S1) was divided for metal analysis $(5 \mathrm{ml})$ and MT analysis $(1 \mathrm{ml})$. Prior to MT dosage, the supernatant aliquot was submitted to heat denaturation and centrifugated to separate the heat-stable proteins from the denatured proteins (Figure 1). The supernatant S2 stemming from the second centrifugation was frozen $\left(-80^{\circ} \mathrm{C}\right)$ until MT quantification. 


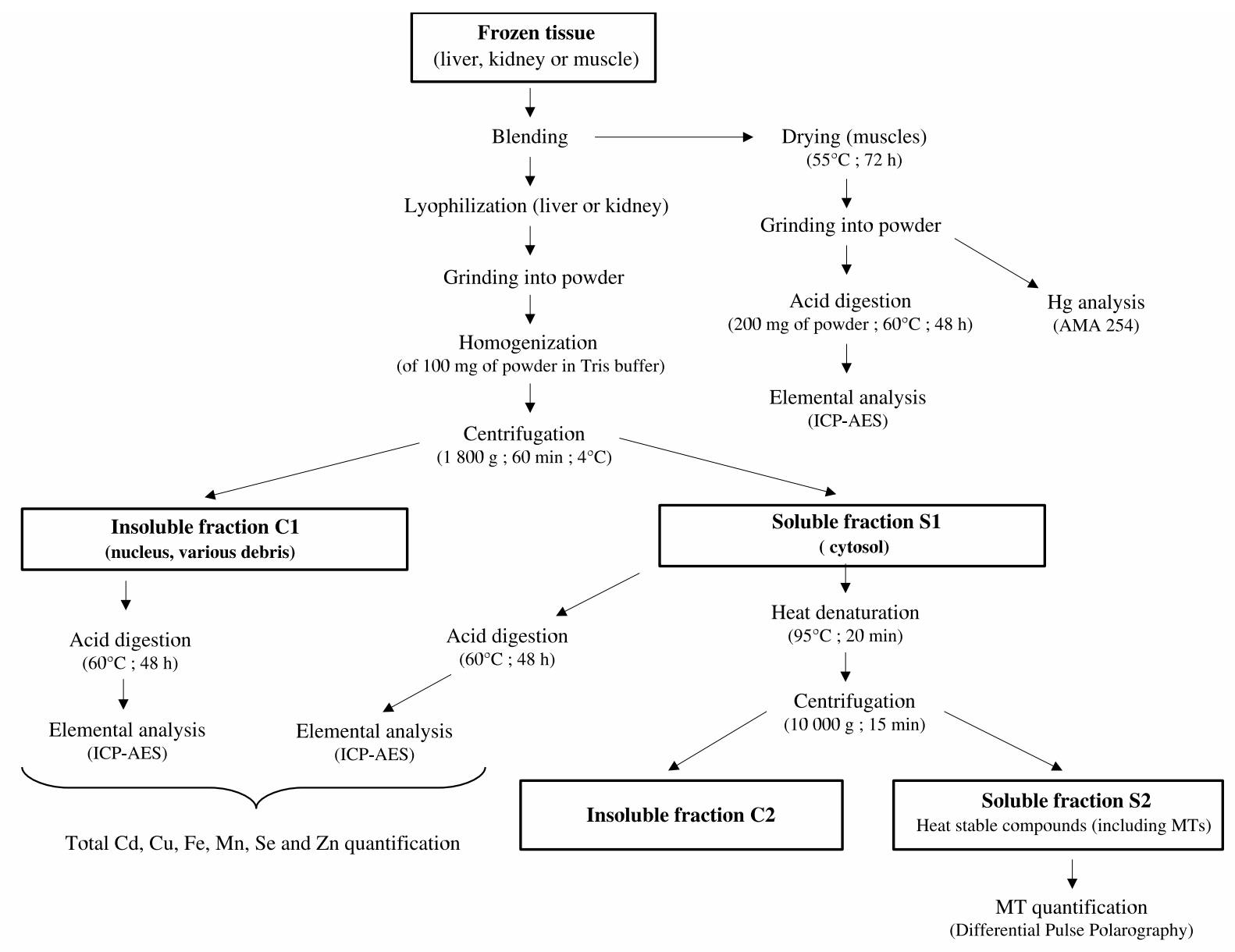

Figure 1: Sample preparation for trace element and MT analysis in seabird tissues.

The analysis of $\mathrm{Cd}, \mathrm{Cu}, \mathrm{Fe}, \mathrm{Mn}, \mathrm{Se}$ and $\mathrm{Zn}$ conducted in S1 and C1 called for an extra step in the preparation protocol. Both fractions were completely dried and digested with $1 \mathrm{ml}$ of $15 \mathrm{~N}$ nitric acid at $60^{\circ} \mathrm{C}$ for $48 \mathrm{~h}$ before being diluted in $10 \mathrm{ml}$ of deionized water.

Metallothioneins were not analyzed in muscle tissue. Muscle samples were thus dried at $55^{\circ} \mathrm{C}$ in an oven before being ground. Two hundred $\mathrm{mg}$ aliquots were digested with $3.5 \mathrm{ml}$ of $15 \mathrm{~N}$ nitric acid and diluted in $10 \mathrm{ml}$ of deionized water.

Accuracy and reproducibility of the preparation were tested by preparing 10 replicates of reference standards (National Research Council, Canada) and 11 blanks along with each set of samples. The sample preparation was done in "metal-free" conditions (Kojadinovic et al., submitted for this volume).

\subsection{Metal analysis}

Cadmium, $\mathrm{Cu}, \mathrm{Fe}, \mathrm{Mn}$, Se and Zn were analyzed in S1 and $\mathrm{C} 1$ by Inductively Coupled Plasma Atomic Emission Spectrometry (ICP-AES Varian Vista Pro CCD). Total levels were obtained by adding the elemental masses found in S1 and $\mathrm{C} 1$ and dividing by the aliquot mass. Total $\mathrm{Hg}$ analyzes were carried out with an Advanced Mercury Analyzer (ALTEC AMA 254). Detection limits and recovery rates are given in Kojadinovic et al. (submitted for this volume). 


\subsection{Metallothionein analysis}

Among the 162 individuals, 70 were analyzed for their hepatic and renal metallothionein levels. Differential pulse polarographic analysis (DPP) was used in order to determine the amount of MTs in the heat-denatured soluble fraction (S2). DPP is a technique based on -SH compounds determination according to Brdička reaction (Brdička 1933) as described by Thompson and Cosson (1984). Model 303A static mercury drop electrode (SMDE) was used. Certified rabbit liver MTs (Sigma Chemical Co., St. Louis, MO) was used to carry out the calibration according to the method of standard additions. The system consisted of a beveled capillary, $\mathrm{Hg}$ working electrode, a platinum counter electrode and an $\mathrm{Ag} / \mathrm{AgCl}$ reference electrode. Results are expressed in $m g$ of MTs per $g$ of dry homogenized tissue. For comparison with concentrations given in relation to wet weight, refer to the mean moisture contents given hereafter: from 66 to $72 \%$ in liver, from 73 to $78 \%$ in kidney and from 65 to $71 \%$ in muscle.

\subsection{Statistical analysis}

Statistical analyses were performed using the GNU R statistical system (R Development Core Team 2005). Data were first checked for normality by means of Shapiro-Wilk tests. In cases of non-departure from normality, parametric tests were used in the subsequent analyses. When Shapiro-Wilk test $p$-values were less than 0.05 , non-parametric analogues were used. Prior to the use of ANOVA for independent samples, in addition to normality, the homogeneity of the variances of the tested samples was checked by means of Bartlett tests. In case of departure from normality or non-homogeneity of the variances, KruskalWallis tests were applied instead.

The significance of differences of MT levels between liver and kidney was tested by means of $t$-tests or Wilcoxon (W) tests according to normality. The influence of species and MC on MT content was tested by means of ANOVA or Kruskal-Wallis tests followed by Tukey's HSD tests. The influence of age, sex and reproductive status was tested by means of $t$-tests or Wilcoxon tests. For each species, dependencies between trace element and MT levels were studied by means of Pearson's linear correlation coefficient. In order to study the factors influencing the distribution of elemental levels between the soluble and insoluble fractions, the latter tests were applied to the ratio between the mass of an element in the soluble fraction and the total mass of this element in both fractions.

Levels of significance of the null hypotheses associated with these tests will be divided into classes of $p$-values represented by the following codes : $N S \geq 0.05 ; *<0.05$; $* *<0.01 ; * * *<0.001$. SD shall stand for standard deviation and CV for coefficient of variation.

\section{Results}

\subsection{Sub-cellular elemental distribution}

The subcellular distribution of analyzed elements is given in Table 3.1 as the percentage of the element recovered in the soluble fraction versus the total amount of metal in the given tissue. It is assumed that, after a centrifugation at $1800 \mathrm{~g}$ for $60 \mathrm{~min}$, the nucleus 
and debris of various origins have sedimented to constitute $\mathrm{C} 1$, whereas $\mathrm{S} 1$ corresponds to the soluble fraction which contains the MTs. Figures 2 and 3 illustrate the levels of these elements in the soluble fraction in relation to the whole tissue levels.

Table 1: Subcellular distribution of hepatic and renal elemental burdens in adult Barau's Petrels, Audubon's Shearwaters and White-tailed Tropicbirds, expressed in percentage of the element recovered in the soluble fraction versus the total amount of metal in the given tissue (Mean $\pm \mathrm{SD})$.

\begin{tabular}{cccc}
\hline & $\begin{array}{c}\text { Barau's Petrel } \\
(\mathrm{n}=6)\end{array}$ & $\begin{array}{c}\text { Audubon's Shearwater } \\
(\mathrm{n}=16)\end{array}$ & $\begin{array}{c}\text { White-tailed Tropicbird } \\
(\mathrm{n}=21)\end{array}$ \\
\hline Liver & & & \\
$\mathrm{Cd}$ & $81 \pm 19$ & $74 \pm 8$ & $84 \pm 4$ \\
$\mathrm{Cu}$ & $61 \pm 11$ & $55 \pm 9$ & $70 \pm 7$ \\
$\mathrm{Fe}$ & $45 \pm 14$ & $33 \pm 14$ & $41 \pm 19$ \\
$\mathrm{Mn}$ & $36 \pm 12$ & $27 \pm 10$ & $33 \pm 15$ \\
$\mathrm{Se}$ & $79 \pm 3$ & $76 \pm 10$ & $60 \pm 8$ \\
$\mathrm{Zn}$ & $58 \pm 10$ & $46 \pm 15$ & \\
& & & $58 \pm 16$ \\
Kidney & & & $46 \pm 15$ \\
$\mathrm{Cd}$ & $65 \pm 15$ & $56 \pm 10$ & $32 \pm 11$ \\
$\mathrm{Cu}$ & $43 \pm 17$ & $25 \pm 12$ & $28 \pm 7$ \\
$\mathrm{Fe}$ & $42 \pm 9$ & $26 \pm 12$ & $66 \pm 13$ \\
$\mathrm{Mn}$ & $14 \pm 5$ & $18 \pm 9$ & $35 \pm 11$ \\
$\mathrm{Se}$ & $78 \pm 12$ & $72 \pm 3$ & \\
$\mathrm{Zn}$ & $21 \pm 19$ & $19 \pm 11$ & \\
\hline
\end{tabular}

The distribution pattern of trace elements between both fractions was similar in the three species. Cadmium, Se and hepatic $\mathrm{Cu}$ were more present in $\mathrm{S} 1$ whereas Fe, Mn, and renal $\mathrm{Cu}$ and $\mathrm{Zn}$ were in a larger part found in $\mathrm{C} 1$. In most cases, the proportion of trace elements in the soluble fraction was higher in liver than in kidney. Furthermore, the concentrations of each element in S1 increased with the total cellular elemental concentrations (Figures 2 and 3). Moreover, the linear correlations between levels in the soluble fraction and in the whole tissue were generally better in liver than in kidney. They were particularly good for $\mathrm{Cd}, \mathrm{Cu}$, Se and $\mathrm{Zn}$ (Figures 2 and 3).

In spite of the general similarity of the results in the 3 species, some differences were observed between the Petrel, the Shearwater and the Tropicbird. The distribution of hepatic $\mathrm{Cd}$ and $\mathrm{Cu}$ was significantly different between Audubon's Shearwater and the White-tailed Tropicbird $\left(P_{\text {Tukey }}: * * *\right)$. In kidney, the two Procellariiforms differed in the distribution of $\mathrm{Cu}\left(P_{\text {Tukey }}: *\right)$ and Fe $\left(P_{\text {Tukey }}: *\right)$, the Shearwater differed from the Tropicbird in the distribution of $\mathrm{Cu}$ and $\mathrm{Zn}\left(P_{\text {Tukey }}: * * *\right)$ and Barau's Petrel differed from the Tropicbird in the distribution of $\mathrm{Mn}\left(P_{\text {Tukey }}: * *\right)$.

The only significant influence of age on trace element distribution, all species combined, was found for Fe $\left(P_{t-t e s t}: *\right), \mathrm{Mn}\left(P_{t-t e s t}: * *\right)$ and Se $\left(P_{\text {Wilcoxon }}: * * *\right)$ in liver. The accumulation of these elements in the soluble fraction was higher in adults than in juveniles.

Sex, across all, did not have an impact on the distribution of trace elements, except for 

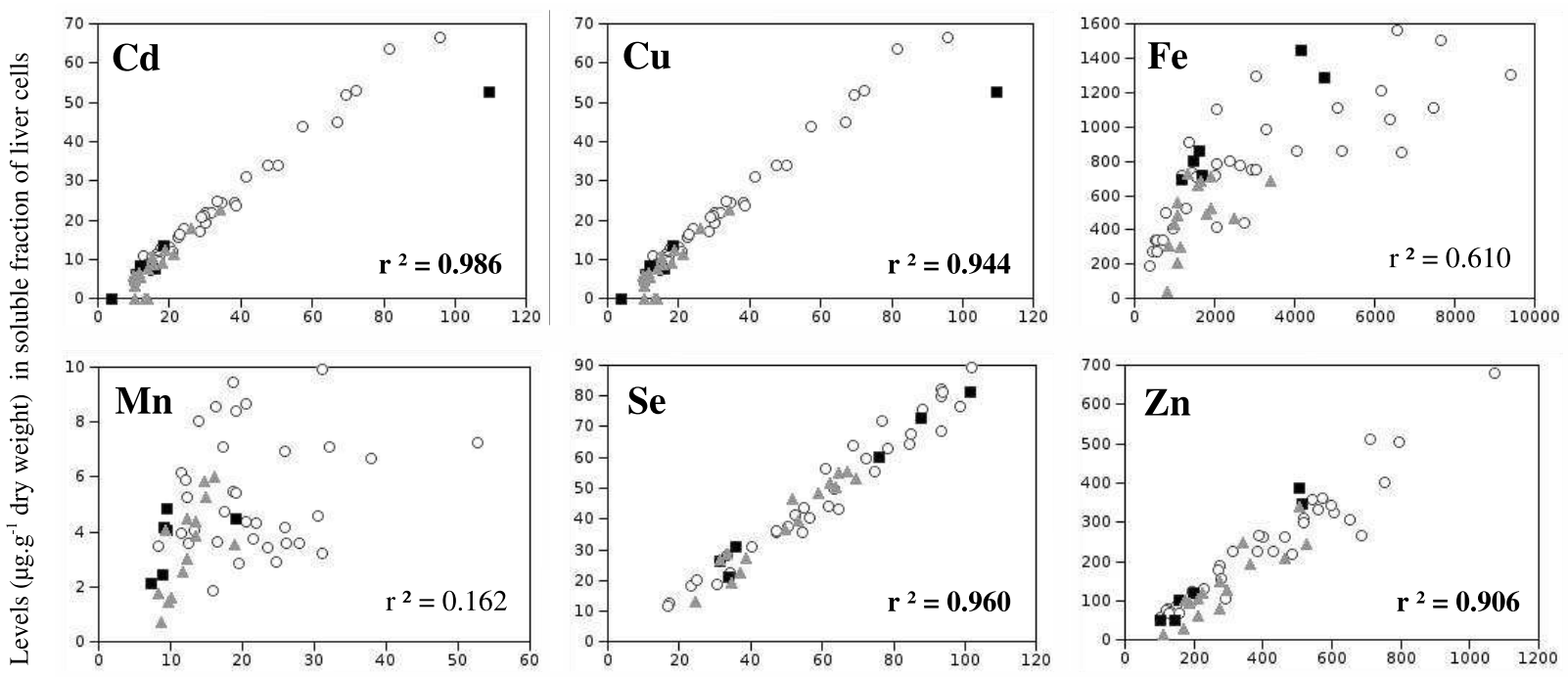

Levels ( $\mu \mathrm{g} \cdot \mathrm{g}^{-1}$ dry weight) in whole liver

Figure 2: Elemental levels in the soluble fraction in relation to their levels in the whole liver of Barau's Petrel, Audubon's Shearwater and the White-tailed Tropicbird.

- Barau's Petrel

$\triangle$ Audubon's Shearwater $\bigcirc$ White-tailed Tropicbird
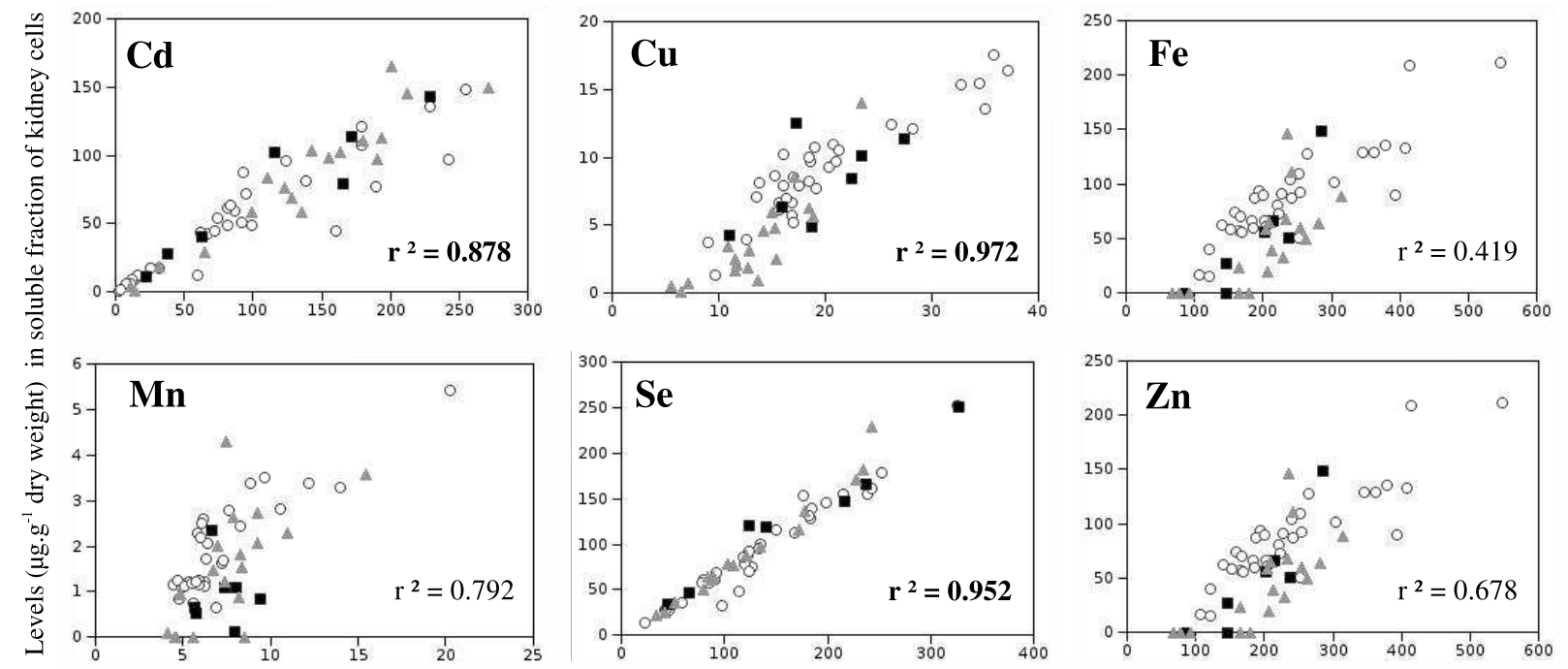

Levels ( $\mu \mathrm{g} \cdot \mathrm{g}^{-1}$ dry weight) in whole kidney

Figure 3: Elemental levels in the soluble fraction in relation to their levels in the whole kidney of Barau's Petrel, Audubon's Shearwater and the White-tailed Tropicbird.

hepatic Zn $\left(P_{t-t e s t}: * *\right)$ which was found to accumulate significantly more in the soluble fraction in females than in males. In the same way, the reproductive status of adults did not influence the distribution of trace elements in the majority of cases. It was however observed that renal $\mathrm{Mn}$ and $\mathrm{Zn}$ levels were higher (resp. $P_{\text {Wilcoxon }}: * *$ and $*$ ) in the insoluble fraction of incubating birds.

The influence of the muscular condition index (MC) on the distribution of $\mathrm{Cd}, \mathrm{Cu}, \mathrm{Fe}$, $\mathrm{Mn}$, Se and Zn was tested. Hepatic Mn, and hepatic and renal Fe, were proportionally more 
present in the soluble fraction than in the insoluble fraction in birds with good muscular condition (resp. P $P_{\text {Kruskal-Wallis }}: * *, P_{\text {ANOVA }}: *$ and $P_{A N O V A}: *$ ). Although less obvious, the same trend was observed for Fe and Mn with the body condition index (BC). In the Tropicbird, hepatic and renal Fe and liver Mn were preferentially accumulated in S1 in larger birds. Indeed, significant positive correlations were found between the bird's body weight and hepatic levels of Fe in S1 $(r=0.723 * * *, n=51)$, the bird's weight and kidney Fe $(r=0.347 *, n=51)$, and the bird's weight and liver Mn $(r=0.651 * * *, n=51)$. The opposite tendency was noticed for kidney and liver Zn in Barau's Petrel (resp. $r=$ $-0.971 * *, r=-0.93 *, n=5)$ but may result from the low number of samples.

\subsection{Metallothioneins}

Metallothionein levels found in liver and kidney of Barau's Petrel, Audubon's Shearwater and the White-tailed Tropicbird are presented in Table 2.

Table 2: Metallothionein concentrations (Mean $\pm \mathrm{SD}, m g \cdot g^{-1}$ d.w.) in liver and kidney of seabirds from Reunion Island. For both tissues, the significance of the level differences among the three species is given in the last column. The letters a and b were used to indicate which species differ in terms of MT levels: species sharing the same letter do not differ significantly.

\begin{tabular}{ccccc}
\hline & Barau's Petrel & Audubon's Shearwater & White-tailed Tropicbird & \\
$\mathrm{n}$ & 16 & 21 & 33 & \\
\hline Liver & & & & \\
Mean $\pm \mathrm{SD}$ & $11.44 \pm 6.22 \mathrm{a}$ & $6.01 \pm 4.87 \mathrm{~b}$ & $9.22 \pm 5.86 \mathrm{ab}$ & ANOVA: $*$ \\
CV\% & 8 & 7 & & \\
& & & & \\
Kidney & & $6.64 \pm 2.94 \mathrm{~b}$ & $5.45 \pm 2.67 \mathrm{~b}$ & ANOVA: $* * *$ \\
Mean \pm SD & $10.39 \pm 6.02 \mathrm{a}$ & 7 & 7 & \\
CV\% & 8 & &
\end{tabular}

The linear correlations between MT and elemental levels are given in Table 3. Positive correlations between total $\mathrm{Cd}, \mathrm{Cu}, \mathrm{Hg}$ and $\mathrm{Zn}$ levels and $\mathrm{MT}$ levels in liver and kidney indicate that MT content of these organs increases with metal levels. At the species level, the highest MT concentrations were found in Barau's Petrel (Table 2) which exhibited the highest $\mathrm{Hg}$ levels of the three species (Kojadinovic et al., submitted for this volume).

Metallothionein levels were significantly different between liver and kidney in the Whitetailed Tropicbird $\left(P_{t-t e s t}: * * *\right)$. However this was not the case for the two Procellariiform species. Besides, MT levels were well correlated between both tissues in the three bird species (Table 3).

In the three species combined, renal MT levels were significantly higher in adults than in juveniles $\left(P_{\text {Wilcoxon }}: * * *\right)$, while there were no significant differences in liver.

As it was observed for trace element levels (Kojadinovic et al., submitted for this volume), the gender nor the reproductive status of the adults of each species had any influence on the MT levels. 
Body condition (BC) did not seem to have any influence on MT levels of each species (Table 3). However, the muscular condition (MC) had an impact on MT concentrations in liver and kidney, the lower MT levels being found in birds with the best MC. Furthermore, significant negative correlations were found between the total weight of the bird and MT levels, especially in liver.

Table 3: Correlations between MT levels and total metal levels, MT levels and the bird's body condition (BC) and, MT levels and the bird's weight. The letters ".L", ".K" or ".M" placed after the abbreviation of an element indicate the tissues (liver, kidney and muscle, respectively) in which the element is considered. PB: Barau's Petrel ; PLB: Audubon's Shearwater ; PQ: White-tailed Topicbird.

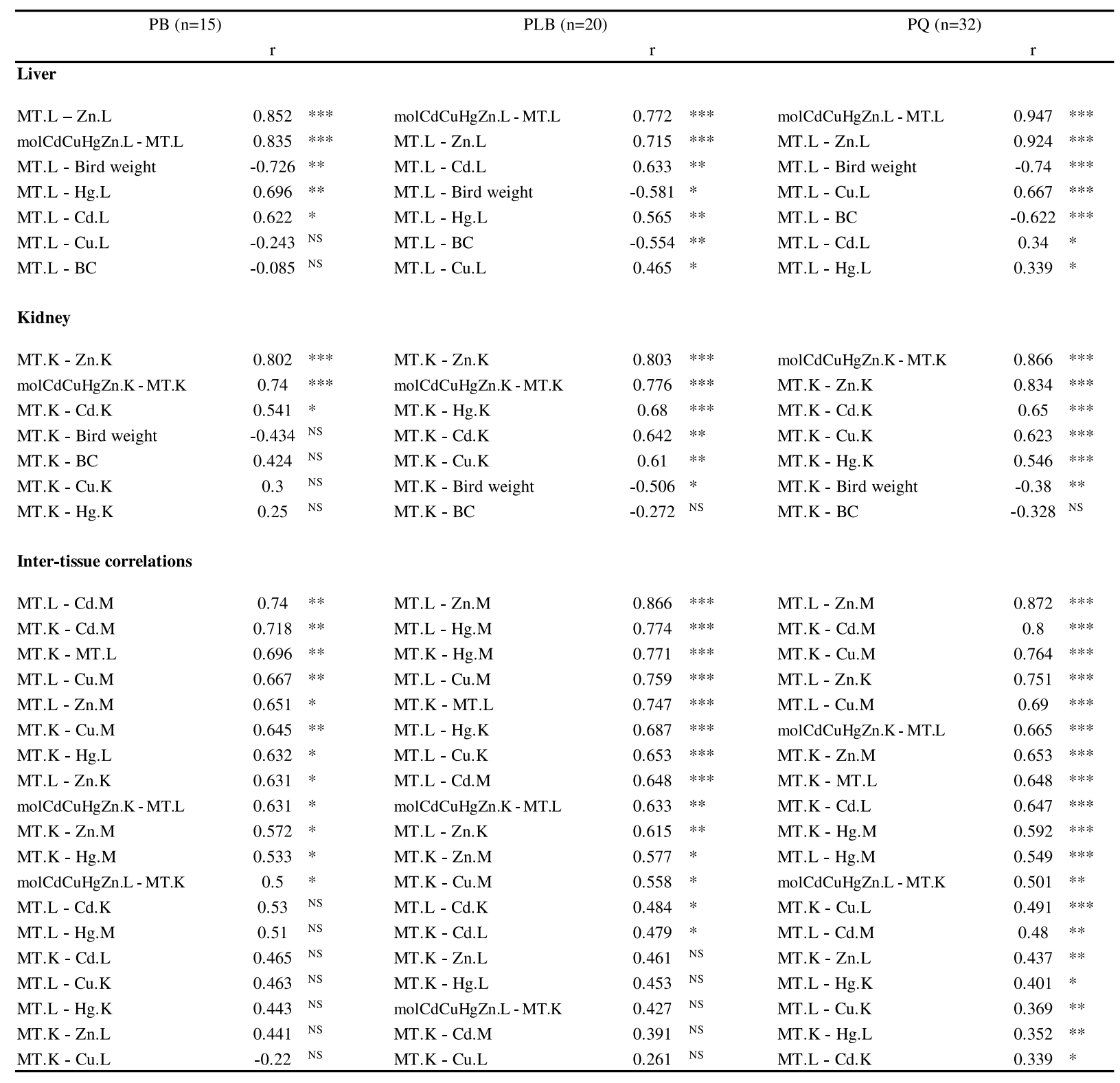

NS: $\mathrm{p}>0.05 \quad *$ : $\mathrm{p}<0.05 \quad * *: \mathrm{p}<0.01 \quad * * *: \mathrm{p}<0.001$

Metallothioneins can bound atoms of $\mathrm{Cd}, \mathrm{Cu}, \mathrm{Hg}$ and $\mathrm{Zn}$ (Hamer 1986). The number of atoms of $\mathrm{Cd}, \mathrm{Cu}$ and $\mathrm{Zn}$ was calculated per gram of dry tissue and summed (denoted by molCdCuHgZn in Table 3), in order to examine the potential linkage of MTs with the 4 atoms simultaneously. Although the degree of correlation varied from one species to the 
other, the same general pairs of well correlated variables appeared, such as MT-Zn in liver and kidney. The summed $\mathrm{Cd}, \mathrm{Cu}, \mathrm{Hg}$ and $\mathrm{Zn}$ atoms were also well correlated with MT levels in the corresponding tissue in all three species. Positive correlations were also found between MT levels in a tissue and metal levels in the other. For example, hepatic MT levels were correlated to muscular $\mathrm{Cu}$ and Zn levels in all species, and renal MT levels were correlated to Cd levels in muscle, liver and kidney.

\section{Discussion}

In addition to its concentration in a tissue, the toxicity of a an element is subject to a number of factors such as the interaction of this element with others, its chemical speciation and its availability, which is dictated by its location in a tissue as well as at a cellular level. The study of elemental subcellular distribution, along with the investigation of potential detoxification processes, is of evident necessity in understanding the path followed by each element in the birds' organism.

The most evident subcellular distribution trend was that, in all three species, the proportion of each element in the soluble fraction was higher in the liver than in the kidney (Table 3.1). The function of each organ probably explains this distribution pattern. On one hand, the liver is an organ of great metabolic activity and a reservoir for essential elements which must be available, and are thus located in the soluble fraction. On the other hand, the kidney is an organ of which the principal function is the excretion of the organism's waste material, but it is also a sink for elements that can not be excreted.

In the three species $\mathrm{Fe}, \mathrm{Mn}$ and renal $\mathrm{Cu}$, were in a larger part found in the insoluble fraction (Table 3.1). The trends observed for these essential metals were similar to those observed in various seabirds and other marine animals (Anan et al. 2002, Ikemoto et al. 2004, Nam et al. 2005) and confirm that these elements are part of the composition of organelle and membrane debris that sedimented during centrifugation. Copper concretions may also account for the renal $\mathrm{Cu}$ found in $\mathrm{C} 1$ (Bremner and Mehra 1991). The muscular condition index had an impact on the distribution of hepatic $\mathrm{Mn}$, and hepatic and renal Fe which were proportionally more present in the soluble fraction than in the insoluble fraction in birds with good muscular condition. Given the importance of pectoral muscles in flight, it can be suposed that when they are well developed and actively used by the bird it enhances metabolic activity in the organism. An active metabolism implies a great demand in energy. It is thus not surprising to find, in these healthy birds, essential metals present in the soluble fraction, where they are more available. Hepatic $\mathrm{Cu}$ was mainly present in S1 where its levels were very significantly correlated to the MT level in the White-tailed Tropicbird. In this bird, the levels as well as the proportion of hepatic $\mathrm{Cu}$ in $\mathrm{S} 1$ were the highest of the three studied species. The correlation between $\mathrm{Cu}$ and MTs observed in liver may be the sign of the regulation of this element in the Tropicbird. In contrast, regulation in the other two species may be less efficient. Further studies are needed to verify this last hypothesis.

Renal Zn was found essentially in the insoluble fraction of the cell in the three seabirds, whereas hepatic Zn's distribution differed among species. Audubon's Shearwater accumulated hepatic Zn preferentially in the insoluble fraction whereas in Barau's petrel and the White-tailed Tropicbird the accumulation was slightly oriented towards the soluble fraction. Audubon's Shearwater was characterized by the lowest levels of MTs and of most elements. Further investigations are needed in order to understand whether this difference 
in the accumulation pattern in Audubon's Shearwater is the result of differences in its storage capacities (e.g. the presence of a smaller amount of ligands in the soluble fraction) or whether these differences result from its diet which is much richer in fish than the other two species. As a general rule, the subcellular distribution of $\mathrm{Zn}$ in the three Reunion species (71 to $81 \%$ of the total $\mathrm{Zn}$ in the subcellular fraction, Table 3.1) seems to be less oriented towards the soluble fraction than in other aquatic birds (Nam et al. 2005). Furthermore, renal $\mathrm{Mn}$ and $\mathrm{Zn}$ levels were higher in the insoluble fraction of incubating birds in relation to birds presenting no incubation patch. These differences in $\mathrm{Mn}$ and $\mathrm{Zn}$ accumulation may be due to the particular physiological state of incubating birds, such as temporarily modified nutritional patterns for example.

Cadmium, Hg and Zn were found to be positively correlated in the seabirds from Reunion Island (data not shown) and had a tendency of increasing in the soluble fraction with the increase of their whole tissue levels (Figures 2 and 3). Although $\mathrm{Zn}$ is considered as the main inducer of MT synthesis, MTs have greater affinities for $\mathrm{Cd}, \mathrm{Cu}$ and $\mathrm{Hg}$ than for $\mathrm{Zn}$. As such, $\mathrm{Cd}, \mathrm{Cu}$ and $\mathrm{Hg}$ ions are expected to displace $\mathrm{Zn}$ ions from Zn-binding sites through a metal-metal exchange reaction (Eaton et al. 1980). The displaced Zn is then available for initiating MT induction (Roesijadi 1996).

The induction of MT synthesis is known to be associated with an increase of the metal resistance of animals (Eaton et al. 1980, Duncan and Klaverkamp 1983). Indeed, MTs main known functions are (i) the homeostatic regulation of intracellular metals by the binding of excess metals that enter the cell and (ii) a "rescue" function for structures impaired by inappropriate metal-binding (Hamilton and Mehrle 1986). The correlations observed between MTs and metal levels in these species suggest that MTs could act as a reservoir for toxic $\mathrm{Cd}$ and $\mathrm{Hg}$ or for the excess $\mathrm{Cu}$ and $\mathrm{Zn}$. Correlation between MT levels and molCdCuHgZn, and between MT and Zn levels, were systematically stronger (higher $r$ values) than correlations between levels of MTs and $\mathrm{Cd}, \mathrm{Cu}$ or $\mathrm{Hg}$ considered separately (Table 3). Consequently, we may conclude that MTs seem to be most often bound (i) exclusively to one or several $\mathrm{Zn}$ ion(s), or (ii) simultaneously to $\mathrm{Cd}, \mathrm{Cu}, \mathrm{Hg}$ and Zn. Furthermore, not only was Cd positively correlated with MT levels in the three species but it was mostly present in the soluble fraction of the cell, where the large majority of the MT burden is found (Table 3.1). Cd-induced renal toxicity is thought to be associated with Cd not bound to MTs (Chan 1998). In this study, the sampled birds died from poaching, collisions or other types of accidents, not indicating fatal intoxication. It can thus be suspected that most of the Cd in S1 was bound to MTs, supporting the hypothesis of a MT-mediated detoxification of Cd. However, MT-Cd compounds seemed unequally distributed between the liver and the kidneys. As noted earlier, MT levels were higher in adults than in juveniles in kidney but not in liver. Interestingly, this does not correspond to $\mathrm{Cd}$ trends where this non-essential metal was more concentrated in adults than in juveniles in kidney as well as in liver (Kojadinovic et al., submitted for this volume). Cadmium found in the liver may be proportionally less bound to MTs in comparison with renal Cd. Cadmium can exit from the liver in the form of Cd-MT through the blood stream and accumulate in the kidney (Chan et al. 1993) which leads us to perceive the liver as a "transition organ" for Cd-MT, and the kidney as a "storage organ" for Cd-MT.

Mercury levels in the storage organs of adult Barau's Petrels (the most Hg-enriched of the 3 species) were very high. However, histological examinations of liver and kidney conducted in seabirds showed $\mathrm{Hg}$ levels similar to those found in Barau's Petrel $\left(21 \pm 28 \mu \mathrm{g} \cdot \mathrm{g}^{-1}\right.$ d.w. vs $24 \pm 14 \mu \mathrm{g} \cdot \mathrm{g}^{-1}$ d.w.) and failed to reveal indications of tissue damage associated with these $\mathrm{Hg}$ levels (Elliott et al. 1992). This might be related to efficient $\mathrm{Hg}$ detoxification 
processes in the studied seabirds. Besides the detoxification of Cd, MTs could also be suspected to play a part in the detoxification of $\mathrm{Hg}$. This is, however, difficult to prove since $\mathrm{Hg}$ subcellular distribution was not determined, and MT-Hg correlation in Barau's Petrel was weak. Moreover, the interaction between $\mathrm{Hg}$ and $\mathrm{Se}$ is considered as the main protective process against Hg toxicity (Magos et al. 1987, Elliott et al. 1992, Kim et al. 1996a). Indeed, $\mathrm{Hg}$ is demethylated in the presence of Se and stored as non-toxic and non-biodegradable, insoluble tiemannite granules in the liver of certain marine mammals and birds (Koeman et al. 1973, Nigro et al. 2002, Ikemoto et al. 2004). A 1:1 molar ratio between Hg and Se in the liver of seabirds strongly suggests the existence of mercuric selenide (HgSe) (Martoja and Berry 1980, Kim et al. 1996a, Decataldo et al. 2004). Such ratios were not found in the Reunion seabirds. Relatively low exposure to $\mathrm{Hg}$ may be the reason for the apparent absence of HgSe granules in the insoluble fraction, which was, in addition, confirmed by little Se accumulation in the insoluble fraction. A threshold level of $100 \mu g . g^{-1}$ d.w. of $\mathrm{Hg}$ was noted in the Black-footed Albatross (Diomedea nigripes), level above which the detoxification of $\mathrm{Hg}$ by Se was triggered (Kim et al. 1996a). Mercury burdens in Reunion adult seabirds were well under this threshold level with hepatic concentrations of $24.31 \mu g . g^{-1}$ d.w. in Petrels, $1.72 \mu g . g^{-1}$ d.w. in Shearwaters and $1.89 \mu g . g^{-1} d . w$. in the White-tailed Tropicbird (Kojadinovic et al., submitted for this volume). In these birds, Se was chiefly compartmentalized in the soluble fraction of the cells (Table 3.1), and Se levels in $\mathrm{S} 1$ increased with levels in the whole liver tissue (Figure 2). Although $\mathrm{Hg}$ subcellular distribution was not studied, significant correlations between $\mathrm{Hg}$ and Se suggest that it has a similar distribution pattern. Nam et al. (2005) interpreted such results as an indication of the formation of $\mathrm{Hg}$-Se complexes bound to thiol-containing glutathione (GSH) molecules (Zilmer et al. 2005) in the soluble fraction. These compounds would act as the precursor of the mineralization of $\mathrm{HgSe}$ in lysosomes. Further investigations on total $\mathrm{Hg}$ and methylmercury $(\mathrm{MeHg})$ distribution in the subcellular fractions should be carried out in liver and kidney of these three species in order to substantiate these hypothesis.

\section{Conclusion}

Many free-living seabirds exhibit relatively high concentrations of trace elements, $\mathrm{Cd}$ and $\mathrm{Hg}$ in particular, with apparently little or no evident ill effects. This is the case of the birds considered during our study, especially Barau's Petrel. In the three seabirds, a MTmediated $\mathrm{Cd}$ detoxification process seems to take place. The involvement of MTs in $\mathrm{Cu}$ and Zn homeostasis was also confirmed. Metallothionein synthesis can be induced by a variety of factors such as various conditions of physical and physiological stress, including starvation (Nordberg 1998, Debacker et al. 2001b). The study of the muscular condition and the body weight of these seabirds confirmed this statement. They should thus be taken into account when comparing MT data. Furthermore, it appears as though a Se-Hg detoxificating interaction exists in the two Procellariiform species.

As a whole, this work showed that trace element availability and detoxification were mainly influenced by the same factors that had an important impact on trace element levels in these birds (Kojadinovic et al., submitted for this volume): age, diet and phylogeny. Trace element levels and MT levels in the three species decreased in the following order: Barau's Petrel, White-tailed Tropicbird and Audubon's Shearwater. This order follows a gradient of (i) weight of the bird (mean weights of adults were resp. $306 \mathrm{~g}, 276 \mathrm{~g}$ and $197 \mathrm{~g}$ ), (ii) percentage of cephalopods in their diet (respectively, 98\%, 80\% and 50\%) and distance of their fishing zones from the coast during the breeding period. However the White-tailed 
Tropicbird stood out in various ways, such as, the strategies developed by the fledgling to cope with fasting (Kojadinovic et al., submitted for this volume), higher percentages of every element in the soluble fraction of its cells, its efficient $\mathrm{Cu}$ regulation, the apparent absence of $\mathrm{Se}-\mathrm{Hg}$ detoxificating interaction in this bird and the potential excretion of Se through eggs in female Tropicbirds (Kojadinovic et al., submitted for this volume). In the light of these results, the Tropicbird's particularities may be linked to the phylogenetic distance which separates this Phaethontidae from the two Procellariidae species.

\section{Acknowledgments}

This research was supported by the Conseil Général de La Réunion. J.K. also benefited from support of the Conseil Régional de La Réunion and the European Social Fund through a PhD grant. The authors would like to thank E. Robert, M. Rouquette, P. Grondin and N. Ghanem in La Réunion for their help in the tissue preparation and C. Churlaud, Centre Commun d'Analyse (La Rochelle), for her assistance with the analyzes on the ICP-AES. We would also like to thank the numerous volunteers who actively participate in the SEOR Petrel rescue program. We are also grateful towards the referees for their helpful comments on the manuscript.

\section{References}

Anan Y., Kunito T., Sakai H., Tanabe S. (2002), Subcellular distribution of trace elements in the liver of sea turtles, Mar. Poll. Bull. 45: 224-229.

Bailey R. S. (1967), The pelagic distribution of seabirds in the Western Indian Ocean, Ibis 110: 492-493.

Barré N., Barau A., Jouanin C. (1996), Oiseaux de la Réunion, Les Éditions du Pacifique, Paris.

Brdička A. R. (1933), Polarographic studies with the dropping mercury method. A new test for proteins in the presence of cobalt salts in ammoniacal solution of ammonium chloride, Collect. Czech. Chem. Commun. 7: 112-128.

Bremner I., Mehra R. K. (1991), Assay of extracellular metallothionein, in Methods in Enzymology, Vol. 205 of Metallochemistry, Part B, Metallothionein and related molecules, Academic Press, San Diego, California, pp. 60-70.

Chan H. M. (1998), Metal accumulation and detoxification in humans, in Metal metabolism in aquatic environments, Ecotoxicology series, 7, Chapman and Hall, London UK, pp. 415-438.

Chan H. M., Zhu L. F., Zhong R., Grant D., Goyer R. A., Cherian M. G. (1993), Nephrotoxicity in rats following liver transplantation from cadmium-exposed rats, Toxicol. Appl. Pharmacol. 123(1): 89-96.

Debacker V., Schiettecatte L.-S., Jauniaux T., Bouquegneau J.-M. (2001b), Influence of age, sex and body condition on zinc, copper, cadmium and metallothioneins in Common Guillemots (Uria aalge) stranded at the Belgian coast, Mar. Environ. Res. 52: 427-444.

Decataldo A., Di Leo A., Giandomenico S., Cardellicchio N. (2004), Association of metals (mercury, cadmium and zinc) with metallothionein-like proteins in storage organs of stranded dolphins from the Mediterranean sea (Southern Italy), J. Environ. Monit. 6(4): 361-367. 
Duncan D. A., Klaverkamp J. F. (1983), Tolerance and resistance to cadmium in white suckers (Castostmus commersoni) previously exposed to cadmium, mercury, zinc or selenium, Can. J. Fish. Aquat. Sci. 40(2): 128-138.

Eaton D. L., Stacey N. H., Wong K. L., Klaassen C. D. (1980), Dose-response effects of various metal ions on rat liver metallothionein, glutathion, heme oxygenase, and cytochrome P-450, Toxicol. Appl. Pharmacol. 50(2): 292-301.

Elliott J. E., Scheuhammer A. M., Leighton F. A., Pearce P. A. (1992), Heavy metal and metallothionein concentrations in Atlantic Canadian seabirds, Arch. Environ. Contam. Toxicol. 22(1): $63-73$.

Gallien I., Caurant F., Bordes M., Bustamante P., Miramand P., Fernandez B., Quellard N., Babin P. (2001), Cadmium-containing granules in kidney tissue of the Atlantic white-sided dolphin (Lagenorhyncus acutus) off the Faroe Islands, Comp. Biochem. Physiol. 130(3): 389-395.

Hamer D. L. (1986), Metallothionein, Ann. Rev. Biochem. 55: 913-951.

Hamilton S. J., Mehrle P. M. (1986), Evaluation of metallothionein measurement as a biological indicator of stress for cadmium in brook trout, Trans. Am. Fish. Soc. 116: 551-560.

Hamza-Chaffai A., Cosson R. P., Amiard-Triquet C., Abed A. E. (1995), Physico-chemical forms of storage of metals $(\mathrm{Cd}, \mathrm{Cu}$ and $\mathrm{Zn})$ and metallothionein-like proteins in gills and liver of marine fish from Tunisian coast: ecotoxicological consequences, Comp. Biochem. Physiol. $111 \mathrm{C}(2): 329-341$.

Hogstrand C., Haux C. (1990), Metallothionein as an indicator of heavy metal exposure in two subtropical fish species, J. Exp. Mar. Biol. Ecol. 138: 69-84.

Ikemoto T., Kunito T., Tanaka H., Baba N., Miyazaki N., Tanabe S. (2004), Detoxification mechanism of heavy metals in marine mammals and seabirds: Interaction of selenium with mercury, silver, copper, zinc, and cadmium in liver, Arch. Environ. Contam. Toxicol 47(3): 402-413.

Jaquemet S., Le Corre M., Weimerskirch H. (2004), Seabird community structure in a coastal tropical environment: importance of natural factors and fish aggregating devices (FADs), Mar. Ecol. Prog. Ser. 268: 281-292.

Kim E. Y., Murakami T., Saeki K., Tatsukawa R. (1996a), Mercury levels and its chemical form in tissues and organs of seabirds, Arch. Environ. Contam. Toxicol. 30(2): 259-266.

Koeman J. H., Peters W. H. M., Koudstaal-Hoi C. H. M., Tjioe P. S., De Goeij J. J. M. (1973), Mercury-selenium correlations in marine mammals, Nature 245: 385-386.

Magos L., Clarkson T. W., Sparrow S., Hudson A. R. (1987), Comparison of the protection given by selenite, selenomethionine and biological selenium against the renotoxicity of mercury, Arch. Toxicol. 60: 422-426.

Martoja R., Berry J. P. (1980), Identification of tiemannite as a probable product of demethylation of mercury by selenium in cetaceans. A complement to the scheme of the biological cycle of mercury, Vie et Milieu 30(1): 7-10.

Mason A. Z., Jenkins K. D. (1995), Metal detoxification in aquatic organisms, in J. Wiley, Sons, eds, Metal speciation and bioavailability in aquatic systems (Tessier A. \& Turner D.R., eds.), IUPAC Series on analytic and physical chemistry of environmental systems, 3, Chichester, England, pp. 479-608.

Nam D.-H., Anan Y., Ikemoto T., Tanabe S. (2005), Multielemental accumulation and its intracellular distribution in tissues of some aquatic birds, Mar. Pollut. Bull. 
Nigro M., Campana A., Lanzillotta E., Ferrara R. (2002), Mercury exposure and elimination rates in captive bottlenose dolphins, Mar. Pollut. Bull. 44(10): 1071-1075.

Nordberg M. (1998), Metallothioneins: historical review and state of knowledge, Talanta 46: 243254.

Osborn D. A. (1978), Naturally occuring cadmium and zinc binding protein from liver and kidney of Fulmarus glacialis, a pelagic North Atlantic seabird, Biochem. Pharmacol. 27: 822-824.

Palmisano F., Cardellichio N., Zambonin P. G. (1995), Speciation of mercury in dolphin liver: a two stage mechanism for the demethylation accumulation process and role of selenium, Mar. Environ. Res. 40(2): 109-121.

R Development Core Team (2005), R: A language and environment for statistical computing, R Foundation for Statistical Computing, Vienna, Austria.

Roesijadi G. (1996), Metallothionein and its role in toxic metal regulation, Comp. Biochem. Physiol. 113C(2): 117-123.

Stahl J., Bartle J. A. (1991), Distribution, abundance and aspects of the pelagic ecology of Barau's Petrel (Pterodroma baraui) in the south-west Indian Ocean., Notornis 38: 211-225.

Thompson J. A. J., Cosson R. P. (1984), An improved electrochemical method for the quantification of metallothionein in marine organisms, Mar. Environ. Res. 11: 137-152.

Vallee B. L. (1995), The function of metallothionein, Neurochem. Int. 27(1): 23-33.

Wenzel C., Adelung D. (1996), The suitability of oiled Guillemots (Uria aalge) as monitoring organisms for geographical comparisons of trace element contaminants, Arch. Environ. Contam. Toxicol. 31: 368-377.

Zilmer M., Soomets U., Rehema A., Langel U. (2005), The Glutathione system as an attractive therapeutic target, Drug Design Reviews 2(2): 121-127. 